\title{
The strengths and weaknesses of user-generated microgames for assisting learning
}

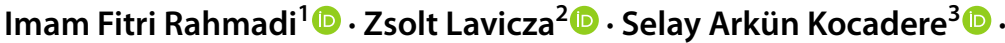 \\ Tony Houghton $^{2} \oplus \cdot$ Markus Hohenwarter $^{2} \mathbb{}$
}

Received: 1 March 2021 / Accepted: 16 June 2021 / Published online: 2 July 2021

(c) The Author(s), under exclusive licence to Springer Science+Business Media, LLC, part of Springer Nature 2021

\begin{abstract}
Recent developments in educational technology have led to a renewed interest in the utilisation of user-generated microgames for facilitating learning. The advantages and disadvantages of microgames which have been voluntarily created, modified, shared and used by users on open learning platforms to support learning are not yet clearly understood. The present study explores the strengths and weaknesses of user-generated microgames for assisting learning followed with some recommendations for the development and effective use of microgames from elementary teacher perspectives. This study is exploratory research conducted within the GeoGebra application with the participation of elementary school teachers from Indonesia. The study found that, on the one hand, user-generated microgames have multiple advantages to support learning mainly by their simplicity and short duration gameplay. On the other hand, the games have several disadvantages, especially due to the lack of content directly related to learning objectives and less interesting interfaces. It is recommended for users of open learning platforms to create more targeted microgames respecting a particular learning objective and for teachers to creatively connect games to learning for mastering knowledge, skills, or literacies.
\end{abstract}

Keywords User-generated microgames · Microgame-based learning $\cdot$ Educational microgames $\cdot$ Serious games $\cdot$ Game-based learning

\section{Introduction}

Recent developments in educational technology have led to a renewed interest in the utilisation of user-generated microgames for assisting learning. A plethora of microgames is now increasingly available on open learning platforms such as Scratch, PurposeGames and GeoGebra which have the potential to facilitate learning

Imam Fitri Rahmadi

imamrahmadi@unpam.ac.id

Extended author information available on the last page of the article 
and enhance student performance. Serious games in general have potential to boost learning performances and cognitive skills (Mayer, 2016; 2019) as well as to increase learner motivation and completion rates (de Freitas, 2006). The availability of serious mini games on open platforms thus appeals to be worth investigating with regard to their capabilities for enriching learning and instruction in formal educational environments.

The notion of integrating microgames into learning has been proposed by Stolovitch (1978) who stated that such very small and short games are viable teaching and learning tools easily integrated into formal learning environments. However, the advantages and disadvantages of microgames which have been voluntarily created, modified, shared, and used by users on open platforms to support learning are not yet clearly understood. Previous research on microgames for supporting learning mainly concern professional microgames designed and developed by publishers or paid individuals (e.g., Brom et al., 2011, 2015; Lukosch et al., 2016; Bellotti et al., 2004). Therefore, exploring the state in which user-generated microgames could contribute to learning is relevant to the present research gaps and future trends in game-based learning.

There are at least three novelties in this exploratory research. Firstly, the study examines very simple learning games instead of general serious games. Due to their simplicity, the games are very easy to integrate by teachers and played by students for supplementing learning. Secondly, neither made by publishers nor paid professionals, the games used in the study were produced by users on open learning platforms. They not only create but also share and use the games at the same time attributed with various Creative Common licenses. Finally, this study accommodates teacher perspectives toward benefits, barriers, and recommendations for the use of educational user-generated microgames. The views of the teachers serve as additional evidence to previous studies that have primarily worked with students.

\section{Theoretical background}

Theories underlie the present study including user-generated microgames and microgame-based learning. For the purpose of this study, the term user-generated microgames was defined in the following section. It is followed by the proposed concept of microgame-based learning which helps to understand the step-by-step of practising the learning model.

\subsection{User-generated microgames}

The concept of user-generated microgames can be explained by elaborating two related terminologies namely user-generated content and microgames. The idea behind user-generated content is to accommodate users as contributors. According to Krumm et al. (2008) and Daugherty et al. (2008), user-generated content (UGC) is a kind of media content that comes from general users or regular people who contribute voluntarily on the Internet by uploading multiform data and information such 
as texts, sound, images, and videos. Furthermore, users not only have the ability to create but also to modify, share, and consume content in individual or collaborative ways (Smith et al., 2012), so they could be called prosumers (Toffler, 1980) who produce and consume content at the same time. Web 2.0 and UGC platforms such as wikis, blogs, forums, and social media made these all possible (Kaplan \& Haenlein, 2010; van Dijck, 2009). Therefore, in addition to publishers or paid professionals, everyone now can publish content on the Internet.

Microgames have a different association in the general and educational context. Generally speaking, microgames are usually associated with simple computer minigames or board games. However, Brom et al. (2011) defines microgames in an educational setting as relatively simple computer games with a specific learning objective that can be played easily and shortly. There is still another microgames definition proposed by Lukosch et al. (2016) for the purpose of training in the workplace as short simulation games which imitate a particular problem in an organisation. Besides the short duration, the micro aspect of microgames indicates that the content is also small or specific (Hug, 2005) and it requires integration to the meso and macro structures of learning (Kapp \& Defelice, 2019). The application of microgames in an educational context can also be categorised as serious games (Richey, 2013) that have the potential to provide meaningful learning experiences (Dörner et al., 2016). This study considers the microgames definition that has been proposed in the setting of education.

Taken together, for the purpose of this exploratory study, user-generated microgames are defined as very simple digital games created by users that provide brief engagement and meaningful experience directed to a specific objective for supporting learning and instruction integrated with existing resources in various environments (Rahmadi et al., 2021). Users in this study are everyone who uses GeoGebra, a dynamic mathematics software that brings together geometry, algebra, spreadsheets, graphing, statistics and calculus in one package (About GeoGebra, 2020) and offers virtual mathematics classroom with real-time learning progress reports (Zöchbauer \& Hohenwarter, 2020). A plethora of user-generated microgames is available on the GeoGebra platform that can be freely modified, shared and used by students, teachers, and general users for educational purposes.

\subsection{Microgame-based learning}

Games have high popularity in terms of supporting learning. Learning through playing games is often called game-based learning (Richey, 2013). It is a learning environment that integrates games into the process of knowledge and skill acquisition (Qian \& Clark, 2016). During the gameplay, students need to solve problems and complete challenges that are relevant to the course content (Wang \& Zheng, 2020). They are immersed in deep interaction with learning content while playing games. However, practicing game-based learning in the classroom does not mean solely giving any games to students which they can freely play during the lesson (Routledge, 2009). Rather, teachers need to regulate the gameplay with respect to the achievement of desired learning objectives. 
Gameplay should be a cyclical process that starts with a briefing, continues to play as the main activity, and ends by debriefing (Routledge, 2009). The briefing is critical to introduce students with the game, activity, and targeted learning goal. They should know what is the game and how to accomplish the challenge within a specific objective. Playing is the main activity where students learn the content during the gameplay. At this step, there are dialectical processes in minds to complete the game with their understanding of learning content. Finally, students and teachers have to debrief what has been done and learned after playing. Debriefing deepens students' acquainted knowledge and skills from playing the game (Crookall, 2010) that may last longer and more engaging than the game itself. Proper debriefing requires a structured strategy, in-depth interaction, sufficient time, and careful implementation (Crookall, 2014).

Although there exists a comprehensive model of game-based learning which focuses on input, process, and outcome (Garris et al., 2002), the Routledge (2009) model has the potential to illustrate the cycle of game-based learning and it can be adopted for microgame-based learning with further adjustment to the characteristics of microgames. The adoption also covers the structure of macro training sessions that are very concise and brief lasting around 15 min (Lukosch et al., 2016). Therefore, the present study considers microgame-based learning that covers steps of briefing, playing, and debriefing around $15 \mathrm{~min}$ in total as can be seen in Fig. 1. The briefing should be very short, followed by microgameplay around $5 \mathrm{~min}$, and debriefing for the rest. Keeping the games simple, brief, meaningful, specific, and integrated is key to microgame-based learning.

\section{Prior studies and the urgency of this study}

To date little attention has been paid to the benefits and drawbacks of user-generated microgames for learning purposes. Existing educational microgames studies concern games that are professionally designed and developed by publishers or professionals in different settings. The studies of Brom et al. $(2011,2015)$ investigated

Fig. 1 Microgame-based Learning

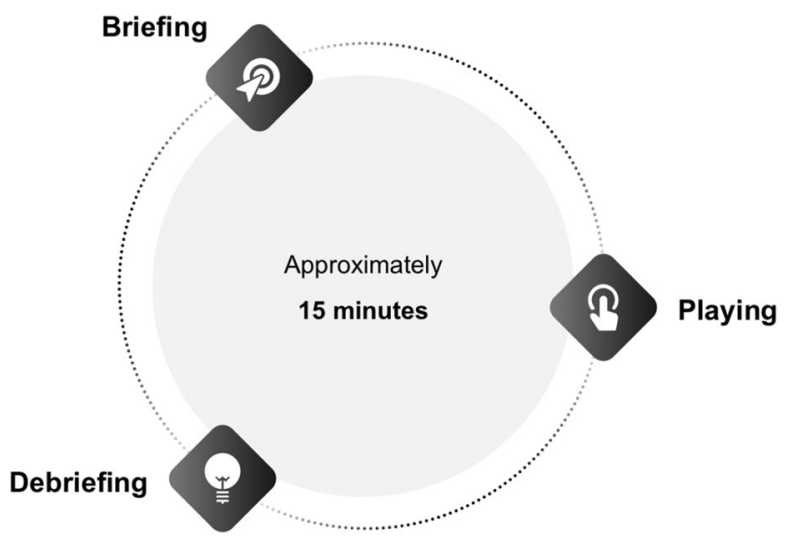


microgames to stimulate engagement and promote knowledge acquisition within individual and collaborative playing at high schools. Its findings reveal that the utilisation of microgames in schools are equally promising whether played individually or collectively for supplementing, reinforcing, and integrating knowledge acquired in the lesson. In the context of workplaces, Zhang and Qin (2021) and Lukosch et al. (2016) reported that integrated microgames into microtraining are recognised as an innovative approach for meaningful learning within microbreaks in fragmented workflows as well as for situated and experiential learning in the workplaces. Furthermore, Chai-Arayalert and Puttinaovarat (2021) and Bellotti et al. (2004) utilised microgames as a medium to interact with arts and cultural heritage played by public. Their studies conclude that microgames could effectively attract public interaction with and enhance awareness towards cultural inheritance. Meanwhile, the microgames used in the previous studies were well-designed games as part of their research projects containing pre-defined topics relevant to the curriculum and learning objectives. It is evident for such games that intentionally produced learning resources by professionals are useful for facilitating teaching and learning in their respective learning environments. The question on the value of the more open way of microgame designs is the subject of this study.

In addition to the minor investigation towards the advantages and disadvantages of microgames produced by regular people for learning, far too little interest has been paid to the microgame explorations from the perspective of teachers, educators, or trainers. Previous research on microgames tends to focus on data gathered from students, workers, or players in general (Zhang \& Qin, 2021; Chai-Arayalert \& Puttinaovarat, 2021; Castelijn, 2017; Lukosch et al., 2016; Brom et al., 2011, 2015; Hussein \& Alhayek, 2012; Bellotti et al., 2004). Those studies merely examined the effect of using microgames to improve particular learner or player performances and behaviours while there were less adequate examinations on the appropriate design, development and integration of microgames. Only the study of Buchtová et al. (2013) which accommodates both student and teacher views, revealed that successful integration of microgames into school and the curriculum greatly depends on the teachers' and students' adequate preparation and positive attitudes toward gamebased learning. The present study extends understanding on the affordances and obstacles of user-generated microgames for assisting learning from teacher outlooks.

Several studies have suggested exploring contributions of various games to learning. It is pivotal to increase comprehension toward the potential of different game types for achieving instructional goals (Connolly et al., 2012). Since the usefulness of purposeful games less likely could be proved by one study, investigating other game types is critical to provide more thorough evidence (Brom et al., 2011). The effectiveness of educational games should be improved and investigated continuously with a variety of recent methodologies in hand (Yu et al., 2020). This study continues the long tradition of research in the area of serious games or game-based learning with the focus on the exploration of microgames created by users of an open learning platform.

The present study also supports the global movement of open educational resources (OER) promoted by the United Nations Educational, Scientific and Cultural Organization (UNESCO). User-generated microgames as OER, intentionally 
designed learning resources that are openly and freely available to educators and learners (UNESCO 2002), empower teachers and students to better perform in teaching and learning especially at this tumultuous time of the Coronavirus disease 2019 (Huang et al. 2020). The teachers could teach beyond old-fashioned textbook boundaries and the students have the opportunity to inclusively access a variety of avant-garde learning resources (EDUCAUSE 2020). Throughout this study, usergenerated microgames were examined regarding their potential in supporting learning and instruction.

Welcoming more viewpoints from teachers is required to better understand their demand as well as to serve fundamental insights into practising microgame-based learning in the classroom. Therefore, this study exclusively explores the strengths and weaknesses of user-generated microgames for facilitating mathematics learning from elementary teacher perspectives. Additionally, recommendations from the teachers for the betterment and effective use of the microgames are also provided. The evidence from this study offers several important insights into the potential and pitfall of very small and short games generated by regular people to enhance instructions. After the explanation of methodological aspects, the findings of the study are presented and discussed in the following sections, and it concludes with practical implications to the creation and utilisation of user-generated microgames for assisting learning.

\section{Method}

The present study is exploratory research conducted within the GeoGebra application with the participation of three elementary school teachers from Indonesia. It is an investigative exploration (Stebbins, 2001) as an inquisitive process about usergenerated microgames for facilitating mathematics learning particularly in elementary schools. The exploration was organised by using an in-depth and semi-structured online interview asking about the strengths and weaknesses of user-generated microgames for supporting learning in elementary schools. In addition, the interview further asked teacher recommendations for the better development and practice of microgame-based learning.

There are three main questions asked during the interview; 1) What are the strengths of user-generated microgames for assisting learning in elementary schools?; 2) What are the weaknesses of user-generated microgames for assisting learning in elementary schools?; 3) What are the recommendations for the development and use of user-generated microgames for assisting learning in elementary schools? These questions act as an opening point to further discuss the strengths and weaknesses of user-generated microgames to support learning with teachers. Elementary teachers who participated in this study were purposely selected with regard to their school locations including urban, suburb, and rural areas. Detailed information about the teachers is presented in the table below.

Table 1 describes the teacher's profiles who participated in the present study. There was a male teacher aged 30 and two female teachers aged 29 years. All teachers hold a bachelor degree in education and have experience in teaching practices 
Table 1 The Profile of Teachers

\begin{tabular}{llllllll}
\hline Teachers & Gender & Age & Education & Experience & Class & School & Location \\
\hline T1 & Male & 30 & Bachelor & 5-10 years & V & Public & Urban \\
T2 & Female & 29 & Bachelor & 5-10 years & III & Public & Suburb \\
T3 & Female & 29 & Bachelor & 5-10 years & V & Public & Rural \\
\hline
\end{tabular}

for around 5 to 10 years. The teachers teach at the class of III and V (8-9 and 10-11 age groups) at public elementary schools in urban, suburban, and rural areas of Indonesia.

Prior to the interview, they were invited to try pre-selected three games created by users on GeoGebra for elementary school level. There were 50 games and other fun activities initially examined, and three of them were selected to show different game designs. The first two games address math skills while the third game has mathematical content. Moreover, GeoGebra was used owing to the plethora of open learning resources not only games but also other learning activities available and ready to be freely integrated by teachers and students for learning. Detailed information about the games is presented in the table below.

Table 2 presents the selected user-generated microgames from GeoGebra with detailed information about its pictures, creators, categories, types, topics, key math skills, and links. The games were created by GeoGebra users for the category of elementary schools within specific types including strategy, puzzle, and racing. Each game has also a certain topic such as logic, square, addition, integers, and subtraction. Furthermore, the games address particular key math skills, namely spatial and number sense. Links to the games are provided to see it on GeoGebra.

An open coding (Glaser, 2016) was employed to analyse the interview results. Respecting the ethical issues, it was explicitly stated before the interview that all collected data is used only for research purposes and the teachers voluntarily participated in this study.

Table 2 Selected User-generated Microgames from GeoGebra

\begin{tabular}{|c|c|c|c|}
\hline Microgames & 1. Mazze 16 - Pikachu & 2. Fit the Four Pieces & 3. Spaceship Racing \\
\hline Pictures & 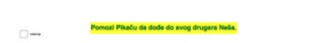 & & \\
\hline Creators & Oliv053c (2016) & Diego Lieban (2019) & Cemccourseware (2016) \\
\hline Categories & Elementary school & Elementary school & Elementary school \\
\hline Types & Strategy & Puzzle & Racing \\
\hline Topics & Logic & Logic, square & $\begin{array}{l}\text { Addition, integers, } \\
\text { subtraction }\end{array}$ \\
\hline $\begin{array}{l}\text { Key math } \\
\text { skills }\end{array}$ & Spatial sense & Spatial sense & Number sense \\
\hline Links & $\begin{array}{l}\text { https://www.geogebra.org/m } \\
\text { /wAAbd4JB }\end{array}$ & $\begin{array}{l}\text { https://www.geogebra.org/m } \\
\text { /d4hsce9f }\end{array}$ & $\begin{array}{l}\text { https://www.geogebra.org/m } \\
\text { /qJR8EbT2 }\end{array}$ \\
\hline
\end{tabular}




\section{Findings}

The forthcoming sections present the gathered data and discuss some critical points from the data. Findings of this study were divided into three corresponding passages with respect to the research aims, namely; 1) strengths of user-generated microgames for assisting learning; 2) weaknesses of user-generated microgames for assisting learning; and 3) recommendations for the development and use of user-generated microgames for assisting learning.

\subsection{Strengths of user-generated microgames for assisting learning}

The main question asked teachers during the interview was: What are the strengths of user-generated microgames for assisting learning in elementary schools? The question was aimed at hearing their perspectives regarding the feasible benefits of user-generated microgames for teachers to facilitate learning. The table below presents several answers from the teachers.

Table 3 reveals the strengths of user-generated microgames for supporting learning from the perspective of elementary teachers. They identified five advantages of the user-created microgames. The microgames are simple and interesting to be played either on smartphones or laptops resulting in more enjoyable mathematics learning. The games motivate students to compete with others, in particular the

Table 3 Strengths of User-generated Microgames for Assisting Learning

\begin{tabular}{|c|c|}
\hline Strengths & Example of Statements \\
\hline Simple and interesting & $\begin{array}{l}\text { T1 - The games are simple and interested to } \\
\text { students. Mathematics learning in schools more } \\
\text { likely to be monotonous and very serious. By } \\
\text { playing these games learning mathematics can be } \\
\text { more enjoyable }\end{array}$ \\
\hline Can be played either on smartphones or laptops & $\begin{array}{l}\mathrm{T} 1 \text { - The three games can be played on smartphones } \\
\text { as well as on laptops } \\
\mathrm{T} 2 \text { - I tried the games on my smartphone and it } \\
\text { can be played. I am sure it can also be played on } \\
\text { laptops }\end{array}$ \\
\hline Motivate students to compete with others & $\begin{array}{l}\mathrm{T} 2 \text { - Students like competition. Elementary students } \\
\text { are invited to compete by playing these games } \\
\text { especially on the racing game. It encourages stu- } \\
\text { dents to be more enthusiastic about learning }\end{array}$ \\
\hline $\begin{array}{l}\text { Short game durations encourage students to replay } \\
\text { the games }\end{array}$ & $\begin{array}{l}\text { T1 - Due to the short duration and the students } \\
\text { already interested, they would like to replay the } \\
\text { games. Students naturally become somewhat } \\
\text { addicted to learning. When the students are inter- } \\
\text { ested in and like the games, they would not like to } \\
\text { stop playing }\end{array}$ \\
\hline Support learning processes in elementary schools & $\begin{array}{l}\text { T3 - Generally, those games can support learning in } \\
\text { elementary schools. Through games, students are } \\
\text { happier and do not recognise that they are learning }\end{array}$ \\
\hline
\end{tabular}


racing game. Their short durations encourage students to replay the games thus they are naturally somewhat addicted to learning while playing. In general, it appears that the games are useful to support learning processes in elementary schools, and that students may not recognise that they are learning by playing the games.

\subsection{Weaknesses of user-generated microgames for assisting learning}

The second question asked the teachers: What are the weaknesses of user-generated microgames for assisting learning in elementary schools? The question was aimed at hearing their views about the possible drawbacks of user-generated microgames for supporting learning. The table below presents several answers from the teachers.

Table 4 reveals the weaknesses of user-generated microgames for supporting learning from the perspective of elementary teachers. It found four major downsides of microgames created by non-professionals for assisting learning. The main drawback is the games that have no direct relation to learning objectives, materials, and curriculum. Moreover, there is a lack of good user interfaces so that the games are less attractive to students. For example, the game design is very small and stiff and thus does not appear in full screen on the smartphone. Its design also seems too simple without special audio and visual effects. Another critical disadvantage is the lack of gameplay instructions leading to teacher uncertainties to play the games. Last but not least, the English language is also being considered as a weakness should English not be the language of instruction in schools.

Table 4 Weaknesses of User-generated Microgames for Assisting Learning

\begin{tabular}{|c|c|}
\hline Weaknesses & Example of Statements \\
\hline $\begin{array}{l}\text { Do not directly relate to learning } \\
\text { objectives and materials as well as } \\
\text { curriculum }\end{array}$ & $\begin{array}{l}\text { T2 - The first two games seem not directly related to learning } \\
\text { objectives in the curriculum. Only the third one I think that } \\
\text { relates to learning materials in elementary schools }\end{array}$ \\
\hline Less attractive interfaces & $\begin{array}{l}\text { T1 - The drawback may be in the user interfaces. It is too } \\
\text { simple without certain notifications or effects when the player } \\
\text { wins } \\
\text { T2 - The games display are very small and stiff that does not } \\
\text { appear in full screen on the smartphone. Particularly in the } \\
\text { first game, it was hard to play } \\
\text { T3 - There are no audio and visual effects in the games }\end{array}$ \\
\hline No playing instructions & $\begin{array}{l}\text { T2 - I was confused and did not sure how to play and what is } \\
\text { the second game objective. In addition, I did not know which } \\
\text { point to be moved in the first game. No instructions to play } \\
\text { in the games } \\
\text { T3 - I was confused about playing the first game and could not } \\
\text { play the second game. The final destination is unclear and no } \\
\text { information about the game rules }\end{array}$ \\
\hline The games are in English & $\begin{array}{l}\text { T2 - Firstly, I thought the games were made specifically for } \\
\text { students in Indonesia. I just realised the games are in English } \\
\text { after trying. I have to reconsidered how to give it to students }\end{array}$ \\
\hline
\end{tabular}




\subsection{Recommendations for the development and use of user-generated microgames for assisting learning}

The third question asked the teachers: What are the recommendations for the development and use of user-generated microgames for assisting learning in elementary schools? The question was aimed at hearing their insights on improvements toward the design and implementation of user-generated microgames for supplementing learning. The table below presents several answers from the teachers.

Table 5 summaries recommendations of elementary teachers towards usergenerated microgames for supporting learning. The teachers have provided some suggestions to enhance the design quality as well as appropriate integration of non-publishers microgames for supplementing learning. In order to create more useful games for learning, users have to generate games with respect to the school curriculum. Creating multiplayer games is another suggestion to enhance player interactivities and challenges. The most recent popular cartoon character should be adapted should the developer wish to create a cartoon-based game. On the other hand, teachers should also be more creative in connecting user-generated microgames with learning materials. Additionally, they have to rule playing time in the classroom and let students play when the time comes.

Table 5 Teacher Recommendations of User-generated Microgames for Assisting Learning

\begin{tabular}{|c|c|}
\hline Recommendations & Example of Statements \\
\hline $\begin{array}{l}\text { Users have to consider curriculum when creating } \\
\text { games }\end{array}$ & $\begin{array}{l}\text { T2 - In my opinion, in order to provide more useful } \\
\text { games for learning, game creators should consider } \\
\text { the school curriculum }\end{array}$ \\
\hline Create multi-player microgames & $\begin{array}{l}\mathrm{T} 1 \text { - For the third game, it would be better if the } \\
\text { opponent is also a student instead of a computer. } \\
\text { So the game will be more interactive. Based on my } \\
\text { experience, students prefer to compete with their } \\
\text { friends }\end{array}$ \\
\hline Using more updated characters & $\begin{array}{l}\mathrm{T} 2 \text { - Should users wish to create a cartoon-based } \\
\text { game, the character must be relevant to the latest } \\
\text { trends. Hence, it is important to choose a cartoon } \\
\text { character that is popular today }\end{array}$ \\
\hline $\begin{array}{l}\text { Teachers should creatively connect games to cur- } \\
\text { riculum }\end{array}$ & $\begin{array}{l}\mathrm{T} 2 \text { - Concerning games that do not directly relate } \\
\text { to the curriculum, teachers are requested to be more } \\
\text { creative in linking the games to learning materials }\end{array}$ \\
\hline $\begin{array}{l}\text { Teachers need to have a specific schedule of play- } \\
\text { ing games in the classroom }\end{array}$ & $\begin{array}{l}\text { T3 - Teachers should have a certain time to control } \\
\text { students in the classroom in terms of playing games. } \\
\text { When the time comes, teachers must keep their } \\
\text { promises }\end{array}$ \\
\hline
\end{tabular}




\section{Discussion}

The main aim of the current study was to explore the strengths and weaknesses of user-generated microgames for facilitating mathematics learning from the perspective of elementary school teachers. In addition, this study asked for recommendations from the teachers for the betterment and effective use of the microgames for learning. The evidence of this study may further support or refute the argument of Stolovitch (1978) who stated that microgames are viable teaching and learning tools easily integrated into formal learning environments, and extend findings of existing microgames research (Chai-Arayalert \& Puttinaovarat, 2021; Zhang \& Qin, 2021; Lukosch et al., 2016; Brom et al., 2011, 2015; Bellotti et al., 2004), with specific interest on the very small and short games made by users or regular people on an open learning platform.

On the one hand, user-generated microgames have multiple strengths to support learning. First, those microgames are simple and interesting to be played either on smartphones or laptops. This finding supports the fact that microgames appeal for learning either in schools (Brom et al., 2011, 2015), workplaces (Lukosch et al., 2016; Zhang \& Qin, 2021) or public spaces (Bellotti et al., 2004). Second, the games have short duration gameplay that encourages students to replay. Although user-generated microgames are short, it turns out that the games have also replayability as do serious games in general. Third, user-generated microgames motivate students to compete with their peers and are supportive of learning in elementary schools. It is evidence for very small and short games to be easily integrated into the teaching and learning processes formal schooling environments (Brom et al., 2011; Van Rosmalen et al., 2014). So far, however, from the perspectives of elementary school teachers, the advantages of microgames created by users for learning are fairly similar to the ones in professionally-made games. The aforementioned benefits, such as motivating and interesting, appear as very common contributions of games to learning (Connolly et al., 2012; Mayer, 2014). Further efforts thus are needed to deeper dig into the specialty of user-generated microgames compared to other microgames. Analysing user-generated microgames from the developer-students point of view might provide critical insight.

On the other hand, there are several weaknesses of user-generated microgames for facilitating learning. One notable drawback is due to the lack of direct relations between the games and learning objectives in the school curriculum. This issue reflects the nature of user-generated content that really depends on the users as content creators (Daugherty et al., 2008; Krumm et al., 2008). They can freely fill in the games with whatever content they want. Furthermore, microgames generated by users suffer under critical design issues in particular toward user interfaces, and it includes the absence of embedded playing instructions into the games. These problems are in line with Hicks et al. (2016) who revealed that users pay less attention to practical components when creating user-generated educational games. However, in this case, it does not mean the mechanics of usergenerated microgames have to be as fascinating as professional-made games. It is recommended to keep microgames easy to play with no pre-required knowledge 
and skills (Rahmadi et al., 2021). Since users from all over the world created the microgames on open learning platforms, the game language that is mostly in English is another critical disadvantage especially for those who are non-English native speakers. Teachers play a vivid role to mediate students' understanding of the games that were presented in their non-native languages. The shortfalls of user-generated microgames in supporting learning serve as new knowledge to ameliorate the problems in the future.

Some feasible solutions are available to improve the design and utilisation of user-generated microgames for supplementing learning. Users are recommended to consider specific learning objectives, multiplayer, and up-to-date characters when creating microgames on open learning platforms. The objective indeed should be specific or small adjusted to the characteristic of microgames content which consists of micro-content (Hug, 2005), a very small content for more individualised learning (Hug \& Friesen, 2007). Teachers are urged to creatively connect user-generated microgames with learning objectives in the curriculum. Users sometimes create microgames with content that is more related to recent critical skills and literacies. Therefore, teachers could connect games not only literally to understand learning materials but to master skills and literacies as well (Qian \& Clark, 2016). Gamebased learning management is pivotal to integrate user-generated microgames effectively into teaching and learning practices. Teachers have to pay great attention to microgame-based learning that consist of the briefing, playing, and debriefing activities (Routledge, 2009) which last around $15 \mathrm{~min}$ (Lukosch et al., 2016). More importantly, as microlearning as concerned, the use of microgames for supplementing learning should be integrated into meso and macro structures of learning (Kapp \& Defelice, 2019). Its integration into existing learning resources already used by students and teachers on daily bases is crucial to the successful implementation of microgame-based learning.

Overall, user-generated microgames can be useful for assisting learning. Nonprofessional-made microgames that are very small in size and short in duration have shared potential with professional-made microgames (Chai-Arayalert \& Puttinaovarat, 2021; Zhang \& Qin, 2021; Lukosch et al., 2016; Brom et al., 2011, 2015; Bellotti et al., 2004) and serious games in general (Connolly et al., 2012; Mayer, 2014) especially their motivational consequences. Likewise, similar to the findings of Brom et al. (2011) and Van Rosmalen et al. (2014), a considerable advantage of either user-generated or publisher-made microgames is their ability to fit learning duration and school curriculum since those are short and no prior knowledge is needed to play the games. Meanwhile, there are limitations on the use of those microgames for knowledge and skills acquisition in a formal learning environment. The game content does not always have a relation to learning objectives and the interfaces can be less appealing. This case is very different to microgames created by publishers and paid professionals as they explicitely consider curricula and learning goals before creating them (Brom et al., 2011, 2015). Suggestions from teachers for the better design and effective utilisation of user-generated microgames should be taken into account in future endeavor. Users should write down related curriculum items when creating microgames while teacher innovativeness is required to connect games either for mastering knowledge, skills, or literacies. As mentioned 
by Buchtová et al. (2013), teachers' preparation and attitudes play significant role on the successful implementation of microgame-based learning.

The present study contributes to the existing knowledge of microgame-based learning by presenting teacher perspectives towards the upside and downside of user-generated microgames for facilitating learning. This study confirms the idea of Stolovitch (1978) who recommends inserting microgames into formal learning environments as those could be integrated with ease. Microgames integration requires minimum effort and time so that may work within a strict learning or working schedule (Zhang \& Qin, 2021). Furthermore, this study extends the earlier findings on microgames research by providing several recommendations to the successful development and utilisation of user-generated microgames for supporting learning. A variety of ways to better create and use such microgames was established to assist users and teachers who wish to generate and benefit from user-generated microgames for their teaching and learning practices. Since this study exclusively accommodated teacher perspectives, it also serves as additional evidence for previous studies that have primarily worked with data from students to determine the way user-generated microgames should be used for teaching.

This study has limitations and future research directions. First of all, the study has the nature of exploratory research thus the results are less generalisable and should be confirmed with other studies. The exploration of user-generated microgames for supporting learning is an ongoing study, which this study was a first step and further in-depth investigations are required. For example, having more experimental and collaborative research with teachers to try the microgames with students and apply suggested recommendations from this study. Second, the interview was conducted with a small number of elementary school teachers in Indonesia who have early experiences with user-generated microgames and microgame-based learning. Therefore, the teachers were less expressive to disclose the real strengths of microgames created by users and their perspectives sound relatively shallow. What they said about the strengths of user-generated microgames was not much different to the benefits of microgames or serious games in general. Another study with more experienced teachers from different countries is needed to closely examine the speciality of user-generated microgames. Finally, this study focused on working with user-generated microgames in a single open learning platform. Exploring microgames that have been generated by users in other platforms such as Scratch and PurposeGames could be a comparative study and would complement the present findings.

\section{Conclusion}

The present study has explored the strengths and weaknesses of user-generated microgames for assisting learning from the perspective of elementary school teachers. This account is followed with some recommendations for the better development and more effective utilisation of the microgames for teaching and learning in formal learning environments. The study found that, on the one hand, user-generated microgames have multiple advantages to support learning mainly by its simplicity and short duration gameplay. On the other hand, the games have several disadvantages, 
especially due to the lack of content directly related to learning objectives and less interesting interfaces. It is recommended for users of open learning platforms to create more targeted microgames respecting a particular learning objective and for teachers to creatively connect game to learning in either for mastering knowledge, skills, or literacies.

Taken all together, the benefits of user-generated microgames for facilitating learning are very similar to the professional-made ones. They share simplicity and shortness to be easily integrated into formal learning contexts. Meanwhile, non-professional-made games are more likely to have substantial drawbacks compared to those of publisher-made ones. Users play a pivotal role on the quality of user-generated microgames. The current findings add to a growing body of literature on microgame-based learning and identify possible directions for future studies. Multiple pathways have been established to guide users in generating relevant microgames for learning and lead teachers practicing microgame-based learning in their classroom. Forthcoming research could explore user-generated microgames in a more experimental and collaborative manner with more teachers from other countries and on other open learning platforms.

Acknowledgements The authors would like to acknowledge elementary school teachers who voluntarily participated in the present study.

Authors' contributions Imam Fitri Rahmadi: designed the research, collected and analysed data, drafted and finalised the manuscript.

Zsolt Lavicza: designed the research and finalised the manuscript.

Selay Arkün Kocadere: critically reviewed and finalised the manuscript.

Tony Houghton: proofread and finalised the manuscript.

Markus Hohenwarter: critically reviewed and finalised the manuscript.

Funding The present work is part of PhD research at the Johannes Kepler Universität Linz funded by the Indonesia-Austria Scholarship Programme (IASP), a joint scholarship between the Indonesian Ministry of Education and Culture (KEMDIKBUD) and Austria's Agency for Education and Internationalisation (OeAD-GmbH) in cooperation with ASEAN European Academic University Network (ASEA-UNINET). Reference number: $M P C-2020-01133$.

Data availability The collected data and its description as well as analysis are included in the text.

\section{Declarations}

Conflict of interest The authors declare that they have no conflict of interest.

Consent to participate All collected data is used only for research purposes and the teachers voluntarily participated in this study.

\section{References}

About GeoGebra. (2020, January 14). GeoGebra. https://www.geogebra.org/about

Bellotti, F., Berta, R., De Gloria, A., Ferretti, E., \& Margarone, M. (2004). Microgames for a compelling interaction with the cultural heritage. Archives \& Museum Informatics, 2, 1-16. 
Brom, C., Preuss, M., \& Klement, D. (2011). Are educational computer micro-games engaging and effective for knowledge acquisition at high-schools? A quasi-experimental study. Computers \& Education, 57(3), 1971-1988.

Brom, C., Levčík, D., Buchtová, M., \& Klement, D. (2015). Playing educational micro-games at high schools: Individually or collectively? Computers in Human Behavior, 48, 682-694.

Buchtová, M., Šisler, V., \& Brom, C. (2013). Educational games and simulations at school: Experimental comparison with classic teaching methods and requirements of successful implementation into school environment and curricula. Proceedings of the 2nd International Workshop on Interaction Design in Educational Environments, 1, 125-132. https://doi.org/10.5220/00045 97301250132 .

Castelijn, J. (2017). Improving Massive Courses with Micro Games: The Effect of Small Serious Games on Student Retention in MOOCs [Master Thesis, Delft University of Technology]. https:// repository.tudelft.nl/islandora/object/uuid\%3Afe27c4c0-a809-446f-8dbd-57ea2a340fc1.

Chai-Arayalert, S., \& Puttinaovarat, S. (2021). A digital micro-game approach to improve the learning of hand-weaving art and history. International Journal of Emerging Technologies in Learning (IJET), 16(08), 4. https://doi.org/10.3991/ijet.v16i08.19795

Connolly, T. M., Boyle, E. A., MacArthur, E., Hainey, T., \& Boyle, J. M. (2012). A systematic literature review of empirical evidence on computer games and serious games. Computers \& Education, 59(2), 661-686.

Crookall, D. (2010). Serious games, debriefing, and simulation/gaming as a discipline. Simulation \& Gaming, 41(6), 898-920. https://doi.org/10.1177/1046878110390784

Crookall, D. (2014). Engaging (in) gameplay and (in) debriefing. Simulation \& Gaming, 45(4-5), 416-427. https://doi.org/10.1177/1046878114559879

Daugherty, T., Eastin, M. S., \& Bright, L. (2008). Exploring consumer motivations for creating usergenerated content. Journal of Interactive Advertising, 8(2), 16-25. https://doi.org/10.1080/15252 019.2008.10722139

de Freitas, S. I. (2006). Using games and simulations for supporting learning. Learning, Media and Technology, 31(4), 343-358. https://doi.org/10.1080/17439880601021967

Dörner, R., Göbel, S., Effelsberg, W., \& Wiemeyer, J. (2016). Introduction. In R. Dörner, S. Göbel, W. Effelsberg, \& J. Wiemeyer (Eds.), Serious games (pp. 1-34). Springer International Publishing. https://doi.org/10.1007/978-3-319-40612-1_1

EDUCAUSE. (2020). 2020 EDUCAUSE horizon report: Teaching and learning edition (pp. 1-58). EDUCAUSE.

Garris, R., Ahlers, R., \& Driskell, J. E. (2002). Games, motivation, and learning: A research and practice model. Simulation \& Gaming, 33(4), 441-467.

Glaser, B. G. (2016). Open coding descriptions. Grounded Theory Review, 15(2), 108-110.

Hicks, D., Liu, Z., Eagle, M., \& Barnes, T. (2016). Measuring Gameplay Affordances of User-Generated Content in an Educational Game. Proceedings of the 9th International Conference on Educational Data Mining, 9, 78-85. https://eric.ed.gov/?id=ED592703.

Huang, R., Liu, D., Tlili, A., Knyazeva, S., Chang, T. W., Zhang, X., Burgos, D., Jemni, M., Zhang, M., \& Zhuang, R. (2020). Guidance on open educational practices during school closures: Utilizing OER under COVID-19 pandemic in line with Unesco OER recommendation. Smart Learning Institute of Beijing Normal University.

Hug, T. (2005). Micro learning and narration. The Proceedings of Fourth Media in Transition Conference, 1-13.

Hug, T., \& Friesen, N. (2007). Outline of a microlearning agenda. In Didactics of microlearning. Concepts, discourses and examples (pp. 15-31).

Hussein, A. J., \& Alhayek, S. K. (2012). The effect of using micro-games of volleyball in improving some life, movement, and performance skills for sixth grade students. Journal of Educational and Psychological Sciences, 13(4), 41-65.

Kaplan, A. M., \& Haenlein, M. (2010). Users of the world, unite! The challenges and opportunities of Social Media. Business Horizons, 53(1), 59-68. https://doi.org/10.1016/j.bushor.2009.09.003

Kapp, K., \& DeFelice, R. (2019). Microlearning: short and sweet. ATD Press.

Krumm, J., Davies, N., \& Narayanaswami, C. (2008). User-generated content. IEEE Pervasive Computing, 7(4), 10-11. https://doi.org/10.1109/MPRV.2008.85

Lukosch, H., Kurapati, S., Groen, D., \& Verbraeck, A. (2016). Microgames for situated learning: A case study in interdependent planning. Simulation \& Gaming, 47(3), 346-367.

Mayer, R. E. (2014). Computer games for learning: An evidence-based approach. The MIT Press. 
Mayer, R. E. (2016). What should be the role of computer games in education? Policy Insights from the Behavioral and Brain Sciences, 3(1), 20-26. https://doi.org/10.1177/2372732215621311

Mayer, R. E. (2019). Computer games in education. Annual Review of Psychology, 70(1), 531-549. https://doi.org/10.1146/annurev-psych-010418-102744

Qian, M., \& Clark, K. R. (2016). Game-based Learning and 21st century skills: A review of recent research. Computers in Human Behavior, 63, 50-58. https://doi.org/10.1016/j.chb.2016.05.023

Rahmadi, I. F., Lavicza, Z., \& Houghton, T. (2021). Towards user-generated microgames for supporting learning: An investigative exploration. Contemporary Educational Technology, 13(3), 1-16. https:// doi.org/10.30935/cedtech/10785

Richey, R. (Ed.). (2013). Encyclopedia of terminology for educational communications and technology. Springer.

Routledge, H. (2009). Games-Based Learning in the Classroom and How it can Work! In Games-based learning advancements for multi-sensory human computer interfaces: Techniques and effective practices (pp. 274-286). IGI Global.

Smith, A. N., Fischer, E., \& Yongjian, C. (2012). How does brand-related user-generated content differ across YouTube, Facebook, and Twitter? Journal of Interactive Marketing, 26(2), 102-113. https:// doi.org/10.1016/j.intmar.2012.01.002

Stebbins, R. A. (2001). Exploratory research in the social sciences. SAGE. https://doi.org/10.4135/97814 12984249

Stolovitch, H. D. (1978). Minigames and microgames for everyone. Audiovisual Instruction, 23(5), 18-20.

Toffler, A. (1980). The third wave: The classic study of tomorrow. Bantam Books.

UNESCO. (2002). Forum on the impact of open courseware for higher education in developing countries: Final report (CI-2002/CONF.803/CLD.1; pp. 1-30). UNESCO. https://unesdoc.unesco.org/ images/0012/001285/128515e.pdf.

van Dijck, J. (2009). Users like you? Theorizing agency in user-generated content. Media, Culture \& Society, 31(1), 41-58. https://doi.org/10.1177/0163443708098245

Van Rosmalen, P., Boyle, E. A., Van der Baaren, J., Kärki, A. I., \& del Blanco Aguado, Á. (2014). A case study on the design and development of minigames for research methods and statistics. EAI Endorsed Transactions on Game-Based Learning, 1(3), e5. https://doi.org/10.4108/sg.1.3.e5.

Wang, M., \& Zheng, X. (2020). Using game-based learning to support learning science: A study with Middle School Students. The Asia-Pacific Education Researcher. https://doi.org/10.1007/ s40299-020-00523-Z

Yu, Z., Gao, M., \& Wang, L. (2020). The effect of educational games on learning outcomes, student motivation, engagement and satisfaction. Journal of Educational Computing Research, 1-25,. https://doi.org/10.1177/0735633120969214

Zhang, Z., \& Qin, L. (2021). InterRings: Towards understanding design micro-games to fit daily work routine. Extended Abstracts of the 2021 CHI Conference on Human Factors in Computing Systems, 1-6. https://doi.org/10.1145/3411763.3451733

Zöchbauer, J., \& Hohenwarter, M. (2020). Developing a collaboration tool to give every student a voice in a classroom discussion. Seventh ERME Topic Conference on Language in the Mathematics Classroom, 1, 195-202.

Publisher's note Springer Nature remains neutral with regard to jurisdictional claims in published maps and institutional affiliations. 


\section{Authors and Affiliations}

\section{Imam Fitri Rahmadi ${ }^{1}$ (D) Zsolt Lavicza ${ }^{2}$ (D) Selay Arkün Kocadere ${ }^{3}$.} Tony Houghton $^{2}$ (D) Markus Hohenwarter ${ }^{2}(\mathbb{D}$

Zsolt Lavicza

zsolt.lavicza@jku.at

Selay Arkün Kocadere

selaya@hacettepe.edu.tr

Tony Houghton

tony.houghton@jku.at

Markus Hohenwarter

markus.hohenwarter@jku.at

1 Universitas Pamulang, Tangerang Selatan, Indonesia

2 Johannes Kepler Universität Linz, Linz, Austria

3 Hacettepe University, Ankara, Turkey 